\title{
Youth personal identity as a factor in the formation of a time perspective
}

\author{
Irina Ralnikova ${ }^{1, *}$, Yana Smirnova ${ }^{1}$ \\ ${ }^{1}$ Altai State University, 656049, 61 Lenin ave., Barnaul, Russia
}

\begin{abstract}
The article presents the results of a study of the personal identity of modern youth as a predictor of the formation of a time perspective. It is shown that in accordance with the nature of the structural organization of personal identity, the time perspective has its own characteristics. Young people with a consistent structural organization of personal identity are focused on a positive past, planning for the future, getting pleasure and enjoyment from life. In the case of a mismatched structural organization of personal identity, young people tend to negatively and pessimistly assess the events of their own past, as well as life in general, as not sufficiently pleasurable, a fatalistic attitude to life prevails, which is expressed in helplessness, hopelessness, lack of purposefulness, leading to a low satisfaction with life in the present and a desire to avoid planning for the future.
\end{abstract}

The modern world is filled with diverse challenges that can influence the process of the formation of the personal identity of young people. Social instability, new risks, as well as the heightened sensitivity of the young generation to the constantly changing conditions of socialization creates a threat to the internal integrity and stability of the individual. As an intrapersonal basis for the integrity of a person in a stream of constant change, personality identity can become. From the standpoint of psychological science, identity is a personal education, a complex phenomenon that integrates a person's ideas about himself, motivational components, value orientations that ensure identity and integrity of a person. [1]. Personal identity reflects both social and individual plan of human life (E. Erickson, J. Marcia, L. B. Schneider, G. M. Andreeva, E. P. Belinskaya, M. S. Yanitsky, A. V. Sery and etc.). Identity is the result of an active reflexive process that reflects the subject's true ideas about himself, his own, and not the imposed path of development, accompanied by a sense of personal certainty, identity and integrity, enabling the subject to perceive his life as an experience of the duration and continuity of consciousness, unity of life goals and everyday actions, actions and their meanings that allow to act consistently (L. B. Schneider) [2]. The search for one's own identity is a basic existential motivation of the individual, associated with the formation of a value-semantic position in relation to oneself and society, with a sense of internal consistency with it in one's own actions and choices (J. Marcia, S. Madi, J. Mead, J. Humbermas, T. Lukman) [2].

* Corresponding author: irinaralnikova @ yandex.ru 
In modern psychological research, the interrelation of such phenomena as identity and time perspective is more and more actively discussed. In the process of life, a person builds an integrated image of himself, identifies his own social and personal position. In this regard, identity is inextricably linked with the temporal aspect of a person's life-support and acts as a determinant of his ideas about his own life in the aspects of the psychological past, present and future, and attitudes towards it. The temporal perspective is a complex formation that unites the temporal and the timeless in man, integrating the personal past, present and future (O. V. Lukyanov). According to A. A. Kronik, "Objectively, a person masters temporary relations in practical activities; subjectively, it is in cognition, where the concept of time is formed and gradually developed, connecting together ideas of the past, present and future" [3, p. 38-39]. These ideas are interrelated and interdependent in the mind and behavior of a person (L. Frank) [4], reflect the features of the "through the vision" from the present to the past and the future (V. I. Kovalev) [5]. The past, present and future are subjectively experienced by a person relatively simultaneously, despite their chronological difference in time (K. Levin) [6]. The time perspective is a set of images of the past, present and future of the individual, integrated at the level of consciousness and subconsciousness [6,7].

As a scientific deepening in the problematics of the relationship between the personal identity of young people and a temporal perspective, we have undertaken a scientific study of the ideas of young men and women about their past, present and future depending on their degree of self-identity - the coordinated and uncoordinated structural organization of personal identity.

The methods of studying thepersonal identity (V. B. Nikishina, E. A. Petrash) and the time perspective questionnaire (F. Zimbardo) modified by A. Syrtsova, E. T. Sokolova, O. V. Mitina) were used as psychodiagnostic research tools. Mathematical-statistical analysis was carried out through the procedure of calculating the student's t-criterion, conducting a correlation analysis. The respondents were men and women aged from 20 to 28 years. Based on the results of the diagnosis of personal identity, the respondents being interviewed were divided into two groups, one of them consisted of 30 people with a coordinated structural organization of personal identity, the other group included 30 people with a uncoordinated structural organization of personal identity.

Mathematical and statistical analysis showed the presence of significant differences in the characteristics of the time perspective in the groups of respondents with a coordinated and uncoordinated structural organization of personal identity (Table 1).

Table 1. The time perspective of young people with a coordinated and uncoordinated structural organization of personal identity.

\begin{tabular}{|l|c|c|c|}
\hline \multicolumn{1}{|c|}{ Scale } & $\begin{array}{c}\text { Coordinated structural } \\
\text { organization of personal } \\
\text { identity }\end{array}$ & $\begin{array}{c}\text { Uncoordinated structural } \\
\text { organization of personal } \\
\text { identity }\end{array}$ & t-criterion \\
\hline Negative past & 2.74 & 3.18 & $5.13^{*}$ \\
\hline Hedonistic present & 3.52 & 3.21 & $4.21^{*}$ \\
\hline Future & 3.60 & 3.10 & $7.20^{*}$ \\
\hline Positive past & 3.63 & 3.29 & $4.04^{*}$ \\
\hline Fatalistic present & 2.70 & 3.11 & $4.86^{*}$ \\
\hline
\end{tabular}

$* \mathrm{p} \leq 0,01$

Men and women with a coordinated structural organization of personal identity are oriented towards a positive past, future, and a hedonistic present. In their life, there are positive memories of the past, a sentimental attitude towards him. The present is filled with carelessness, young people prefer to spend the time on getting pleasure in the present, not to 
worry about the consequences of the decisions made and the actions done. The future in the group of respondents in a coordinated structural organization of personal identity has a broad perspective, they plan their lives, strive to achieve their goals.

In the case of a uncoordinated structural organization of personal identity, the profile of the temporal perspective of young people shifts towards a more pronounced orientation towards a negative past and a fatalistic present. These respondents tend to negatively and pessimistically assess the events of their own past, as well as life in general, as not sufficiently pleasurable. The fatalistic attitude reflects a helpless and hopeless attitude to the future and to life in general, as well as a lack of determination, which entails low satisfaction with life in the present and a desire to avoid planning the future. Indicators on the scales of the positive past, future and hedonic present cannot be called low in this group of respondents. They are statistically less pronounced focus on the future and focus on the present as a source of pleasure and positive emotions in life compared to a group of respondents with a coordinated structural organization of personal identity. At the same time, high values on the scales of the negative past and the fatalistic present lead to a general "disharmonization" and inconsistency of the temporal organization of the life of young men and women who have a uncoordinated structural organization of personal identity.

The analysis of the intercorrelations existing the scales of the time perspective questionnaire in groups with a coordinated and uncoordinated structural organization of personal identity revealed the differences in the composition of the relationships of the studied temporal parameters with each other (Table 2, 3).

Table 2. Intercorrelation of temporal perspective parameters in the group of respondents with a coordinated structural organization of personal identity.

\begin{tabular}{|c|c|c|c|c|c|}
\hline$\frac{0}{\tilde{J}}$ & 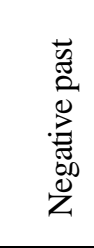 & 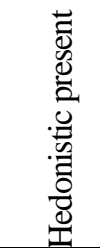 & $\underset{\text { 至 }}{\stackrel{\Xi}{E}}$ & 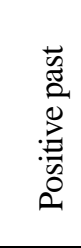 & 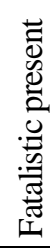 \\
\hline Negative past & $\mathbf{x}$ & & & & \\
\hline Hedonistic present & $0.24 *$ & $\mathbf{x}$ & & & \\
\hline Future & $0.39 *$ & 0.18 & $\mathbf{x}$ & & \\
\hline Positive past & 0.05 & $0.47 *$ & $0.30 *$ & $\mathbf{x}$ & \\
\hline Fatalistic present & $0.47 *$ & $0.35 *$ & 0.06 & 0.18 & $\mathbf{x}$ \\
\hline
\end{tabular}

$* \mathrm{p} \leq 0.05 ; * * \mathrm{p} \leq 0.01$

With a coordinated structural organization of personal identity, the correlation structure is more dense, if compared to the uncoordinated, time parameters are interconnected by direct correlations. In the case of leading temporal parameters (hedonistic present, future, positive past) for this group of respondents, the analysis of the intercorrelation matrix made it possible to clarify that a positive reconstruction of past life events, young people's orientation towards future planning, on the one hand, and a pronounced hedonistic orientation to the present, on the other hand are closely related. These parameters in the aggregate set the features of the time perspective of young people with a coordinated structural organization of personal identity (Table 2). At the same time, in addition to the positive past, the hedonistic mood of young people is closely connected with the fatalistic attitude reflecting helplessness, hopelessness towards the future and towards life in general, as well as the lack of determination. This, in our opinion, is an alarming moment, embracing the whole psychology of a person, capable of becoming an obstacle in the way of a young man 
experiencing his integrity and self-awareness as a whole. The results show that the structural organization of the personal identity of the youth of this group, although it is fixed as coordinated, nevertheless is on the way of becoming, in the process of a regular search for a solution to the problems. The coordinated organization of personal identity can act as the basis for the formation of a balanced time perspective, set the coordinates of a person's psychological stability in a changing world.

In the case of a uncoordinated structural organization of personal identity, the correlation structure is focused on the direct and inverse relationships of the fatalistic present with all the studied parameters of the time perspective (negative past, hedonistic present, future, positive past) (Table 3).

Table 3. Intercorrelation of temporal perspective parameters in the group of respondents with uncoordinated structural organization of personal identity.

\begin{tabular}{|c|c|c|c|c|c|}
\hline $\begin{array}{l}\frac{0}{J} \\
\text { ñ }\end{array}$ &  & 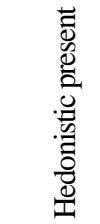 & 总 & 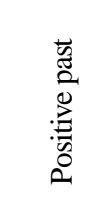 & 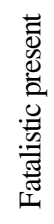 \\
\hline Negative past & $\mathbf{x}$ & & & & \\
\hline Hedonistic present & 0.07 & $\mathbf{x}$ & & & \\
\hline Future & 0.02 & $-0.31 * *$ & $\mathbf{x}$ & & \\
\hline Positive past & $-0.32 * *$ & 0.13 & $0.18 *$ & $\mathbf{x}$ & \\
\hline Fatalistic present & $0.48 * *$ & $0.34 * *$ & $-0.25 * *$ & $-0.18 *$ & $\mathbf{x}$ \\
\hline
\end{tabular}

$* \mathrm{p} \leq 0,05 ; * * \mathrm{p} \leq 0,01$

So, the fatalistic attitude to the future and to life in general, the belief in the predestination of the future, the submissive and humble living of the present, low satisfaction with their present life, the opinion that it will not change for the better, is associated with understanding the past as a negative period of life and orientation on pleasure and carelessness, weakening of goal-setting and motivation for planning the future, as well as the predominance of the position of negativism in assessing life events. At the same time, in the studied group there is an inverse intercorrelation of such parameters of the temporal perspective of young people as the hedonistic present and future, indicating that without the proper attention and effort put into designing your life path, it is not possible to achieve a good result in any business. So, young men and women with a uncoordinated structural organization of personal identity have an unbalanced temporal perspective, the main function of which is related to the regulation of human activity in the present in order to implement the planned life plans for the future remains unfulfilled.

Summarizing the obtained results of the study, we can conclude that the structural organization of personal identity acts as a predictor determining the nature and content of the mental reconstruction of the past, present and future by the person in his field of consciousness, as well as a sign of attitude to these temporal modes and their significance. Systems of interrelation of parameters of a temporal perspective are different in the case of the coordinated of the structure of personal identity and in case of its uncoordinated. The coordinated structural organization of personal identity sets the benchmarks for young people for the positive past, future and the hedonistic present, serves as the basis for the formation of a balanced time perspective and psychological stability. In the case of an uncoordinated structural organization of personal identity in young men and women, a particular feature of the temporal perspective profile is the pronounced orientation towards 
the negative past and the fatalistic present, which is manifested in the reconstruction of past events in a negative perspective and in avoiding goal-setting for the future; the presence of high indicators of "negative" aspects of a temporal perspective (negative past, fatalistic present) leads to a general disharmonization and contradictory organization of life.

\section{References}

1. Ts. P. Korolenko, N. V. Dmitrieva, E. N. Zagoruiko, Identity in health and pathology (Publishing House of the Novosibirsk State Pedagogical University, Novosibirsk, 2000)

2. L. B. Schneider, Identity (Publishing House of the Moscow Psychological and Social Institute, Moscow, 2008)

3. E. A. Golovakha, A. A. Kronik, Psychological time personality (Meaning, Moscow, 2008)

4. L. K. Frank, Journal of social Philosophy, 4 (1939)

5. V. I. Kovalev, Category of time in psychology (personal aspect): categories of materialistic dialectics in psychology (1988)

6. K. Lewin, Time perspective and morale: civilian morale (1942)

7. K. A. Abulkhanova-Slavskaya, T. N. Berezina, Personality time and life time (Aletheia, St. Petersburg, 2001) 